\section{Flexible innovation in $2 \mathrm{D}$ and 3D impressions}

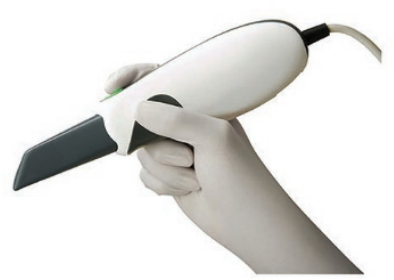

If you want the flexibility to choose between 2D and 3D digital impressions, with a fully integrated and seamless workflow, you need the CS 3500 intraoral scanner from Carestream Dental.

Available as part of the complete CS Solutions portfolio or as a stand alone solution, the innovative technology features high-angulation precision scanning of up to 45 degrees and to a depth from -2 to $+13 \mathrm{~mm}$. It also incorporates a unique light guidance system that aids the capture of data for perfect images first time.

Current users of the CS 3500 have described it as 'as great piece of equipment' that 'improves patient comfort' and 'adds a WOW factor to your practice.

Find out how it could enhance your dentistry today by contacting the team from Carestream Dental.

For more information, contact Carestream Dental on 08001699692 or visit www.carestreamdental.co.uk.

\section{Support every step of the way}

Tavom UK specialises in supplying and installing quality dental practice cabinetry, such as the Classic C3000 range.

To ensure you get what is best for you and your practice, the dedicated Tavom UK team work with you every step of the way, from choosing the cabinets to delivering and fitting them. A dental practice design service is also available for those looking to refurbish or add another surgery.

Plus, if you plan to expand in the future, flexibility can be incorporated into any layout and design.

\section{Peace of mind}

Most dentists will only purchase one or two dental treatment centres in their professional life, so will want the reassurance that their investment is protected for as long as possible.

Belmont offers free extended warranties on its equipment. All chairs and operating lights are covered for five years, and all X-ray units for two years. They do this because they are completely confident in the quality of their equipment and know that failure within this timescale is almost unheard of.

To reassure practices even further, the company has also recently achieved an additional ISO standard, which entails further electrical safety checks being carried out. It also ensures that all products are totally traceable from the supply chain to the end user. This is
When it comes to installation, all cabinets are delivered fully assembled to minimise disruption and streamline the fitting process.

As for the quality of the Classic C3000 range, it offers adjustable levelling feet, is HTM 01-05 infection control compliant, easy to clean, durable and aesthetically pleasing for both professional and patient.

If you are interested in refurbishing or expanding your practice, contact Tavom UK to discuss your options.

Contact Tavom on 08707521121 or visit www.tavomuk.

not an industry standard, or one common to all manufacturers.

Call 02075150333 or visit www.belmontdental.co.uk

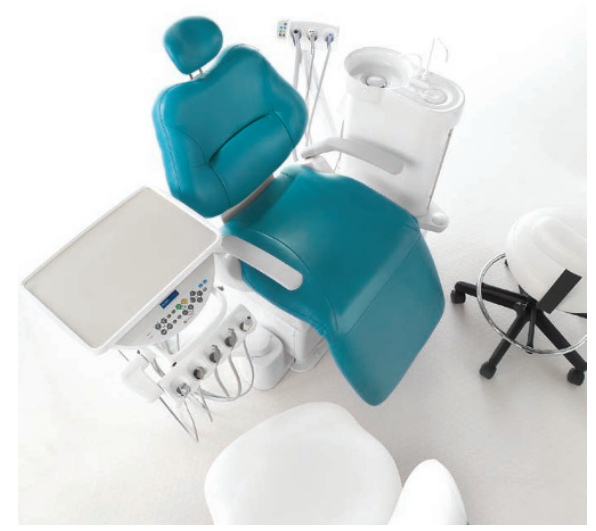

\title{
For specialist tax planning advice
}

Conradi Morrison \& Co specialise in assisting dental practices and dental associates and advise on financial matters such as tax planning.

As most practices' and associates' financial year ends are on 31 March to bring them in line with the tax year end of 5 April, this month is important to consider any tax planning prior to the year end.

One of the most important opportunities is the purchase of fixture and fittings and equipment prior to 31 March 2017 in order to obtain the annual investment allowance (AIA). For the tax year 2016/17, the total AIA that can be claimed is $£ 200,000$. This allowance is claimable against profit and means the total taxable profit can be reduced by that amount. To claim the allowance the equipment, plant office and fittings must be owned by the business. However, it does not have to have been paid for. This means it may be purchased through a HP agreement or a loan but it must not have been purchased through a leasing agreement.

Most practices are aware of the type of equipment and fixtures and fittings for which they can claim but many associates forget the small equipment which is not supplied by the practice for which they work but for which they personally pay for. These may include sophisticated cameras to take photographs of their patients' teeth, tablets for finding information on the web, computers and printers, desks and chairs for use when dealing with preparation of their own tax affairs in their home, professional courses which they have to attend and dental equipment which they have purchased themselves and also mobile and fixed telephones.

If for some reason the practice or associates have not planned correctly and have purchased the capital item just after 31 March which is their financial year end, they could consider changing the financial year end to 5 April to ensure that an AIA relief claim can still be made for the tax year 2016/17.

Conradi Morrison \& Co would be very glad to meet you and discuss the possibility of tax planning in your business. Call 01322278188 to arrange a meeting without charge. 